\title{
The Effect of Marketing Activities on the Brand Recognition, Brand Familiarity, and Purchase Intention on the SNS of Franchise Companies
}

\author{
Tae Yoo CHUN ${ }^{1}$, Dong Keol LEE ${ }^{2}$, No Hyun PARK ${ }^{3}$
}

Received: August 01, 2020 Revised: October 05, 2020 Accepted: October 15, 2020

\begin{abstract}
The purpose of this study is to find out how SNS marketing activities affect brand recognition, brand familiarity, and purchase intention for consumers who have purchased products from franchise chicken stores, including whether there is a moderating effect according to gender. SNS marketing activities were set up by configuring three attributes which are, SNS advertising, SNS information, and SNS events as sub-factors. For empirical analysis, a survey was conducted on SNS users, and SPSS/AMOS statistical programs were employed for the data analysis. First, the result of the empirical analysis showed that SNS advertising, SNS information, and SNS events have a significant positive effect on brand recognition. Second, it was found that the SNS events had a significant positive effect on brand familiarity. Third, it was found that SNS advertising has a significant positive effect on purchase intention. Fourth, it was observed that brand recognition has a significant positive effect on brand familiarity. Fifth, it was found that brand recognition and brand familiarity have a significant positive effect on purchase intention. Sixth, it was found that gender plays a significant role in the relationship between these constructs. Therefore, it can be assumed that the hypothesis presented in this study is sufficiently proven.
\end{abstract}

Keywords: SNS Marketing, Brand Recognition, Brand Familiarity, Purchase Intention, Gender

JEL Classification Code: L10, L15, L80, M31, M37

\section{Introduction}

Recently, a network has arrived that allows anyone to purchase desired products by quickly acquiring information from companies or stores in all regions of Korea with computers and smart devices. This is a social phenomenon due to the high penetration rate of smart devices, along with the expansion of Internet wired and wireless networks. As of 2019, the number of global social network service (SNS) users is estimated at 3.8 billion, which accounts for $49 \%$ of the global population (We are

${ }^{1}$ First Author, Professor, The Graduate School of Industry, Sejong University, Republic of Korea. Email: chun109@sejong.ac.kr

${ }^{2}$ Ph.D. Student, Cooperative Course for Urban/Real Estate Study and Commercial Science, Sejong University, Republic of Korea. Email: jopabnamu@naver.com

${ }^{3}$ Corresponding Author, Visiting Professor, The Graduate School of Industry, Sejong University, Republic of Korea [Postal Address: 209 Neungdong-ro, Gwangin-gu, Seoul, 05006, Republic of Korea] Email: parknhn@hanmail.net

(c) Copyright: The Author(s)

This is an Open Access article distributed under the terms of the Creative Commons Attribution Non-Commercial License (https://creativecommons.org/licenses/by-nc/4.0/) which permits unrestricted non-commercial use, distribution, and reproduction in any medium, provided the original work is properly cited.
Social, 2020). The size of the market using SNS is also reaching about $\$ 98$ billion, an increase of $23 \%$ compared to 2018 (Statista, 2020).

According to the National Information Society Agency (2019), the Internet access rate per household in Korea reaches $99.5 \%$ of the total of 19.75 million households, and the Internet usage rate reaches $91.5 \%$. Among Internet users, the proportion of men who are aged there and above are $93.9 \%$, which is $4.8 \%$ higher than that of women. The primary purpose of using the Internet is communication (94.8\%), data and information acquisition (93.7\%), and leisure activities (92.5\%) in that order. Among them, 95.9 percent of users aged six and above use SNS. As for the functions that SNS users use a lot, $100 \%$ for chatting, $76 \%$ for using photos and videos, $45 \%$ for voice and video calls, $36.2 \%$ for games, and $25.2 \%$ for shopping, etc. $89.6 \%$ of the population aged three and above used smartphones, and $90.4 \%$ accessed the mobile Internet through smartphones, tablets, and smartwatches. SNS has grown into a primary medium of communication in the daily life of consumers with the easy availability of the internet networks. Users spend an average of 10 hours and 47 minutes per week for communication, leisure, learning, finance, and shopping using SNS (National Information Society Agency, 2019). 
SNS can provide a low-cost, high-efficiency marketing opportunity to small business owners. Online shopping companies also conduct marketing by sharing information search before purchase and reviews after purchasing to consumers, which is useful in marketing activities. Companies continue to study ways to establish and utilize marketing strategies using SNS media. Companies that have used traditional media advertisements such as TV, radio, newspapers, and magazines for their existing offline consumers have also become aware of SNS as an essential channel to efficiently increase corporate profits and attract new customers by using online marketing using SNS media. Franchise companies, which have long used newspapers, magazines, and flyers for a large number of unspecified consumers, have also been quickly preparing and executing Internet-based real-time online marketing, focusing on new media channels such as SNS and YouTube recently. In particular, large franchise headquarters, which are aware that consumers' buying patterns and oral intentions are changing through advertisements, information, and events on SNS media, have secured various SNS channels, actively engaging in marketing through them. Recently, it has been observed that new entrepreneurs actively use SNS media as a tool for market research and market development before entering new markets.

Examining the previous studies, most of the research on SNS marketing activities focused on foodservice companies and service companies, but there are fewer researches on franchise companies. Therefore, the purpose of this study is to investigate the effect of the social media marketing activities of franchise chicken stores on brand recognition, brand familiarity, and purchase intention, and to find out whether gender plays a moderating role in the relationship between these concepts.

\section{Theoretical Background}

\subsection{SNS Marketing Activities}

SNS (Social Network Service), a social network, refers to a community on the Internet that shares information mainly through the Internet or establishes social connections through free communication. SNS is generally referred to as an Internet network service that supports communication and interaction among individuals (Royle \& Raing, 2014). National Information Society Agency (2019) introduces that SNS is an activity that strengthens relationships with friends, colleagues, and acquaintances on the Internet or shares communication and information by forming a new human network, including merely viewing and observing contents presented by others, introducing services such as Kakao Talk, Facebook, Line, NateOn, Telegram, Band, Instagram, YouTube, Internet cafe, blog, and Twitter are examples of
SNS. With the drastic increase of users and the attribute of a continuous personal network, SNS is gradually expanding its range to become increasingly important information sharing and business areas (Cho, 2019).

Companies are using social networking sites, portal sites, and mobile devices to carry out marketing activities based on digital technology. Delu (2019) suggested that SNS marketing is a plan and activity to advertise products, companies, and brands using SNS such as Twitter, Facebook, and Instagram. Overcoming the space and time constraints of personal networks, consumers have begun to use SNS for various evaluations of products. Through SNS, consumers' responses and assessments can be immediately checked, enabling more efficient production planning and marketing. SNS marketing activities are easy to grasp consumers' needs, and can reflect consumers' opinions in product development and secure diversity in customer management.

The prior studies of SNS marketing activities are as follows. Ahn \& Yang (2019) argued that the feature of mobile SNS positively affects purchase intention in the agrifood sector and that the advertising attributes of SNS have a significant effect on purchase intention and brand attitude. Jung, Jung, \& Han (2019) reported that SNS marketing activities of airlines have a positive causal relationship with brand value, brand attitude, and brand loyalty.

According to the results of previous research analysis, in this study, the SNS marketing activities of franchise companies were derived as three attributes: SNS advertisement, SNS information, and SNS event. First, SNS advertising was defined as advertising, banners, and advertisements for companies or products provided by franchise companies on SNS media. SNS information was defined as news about companies or products provided by franchise companies on SNS media and daily information. Besides, SNS events were defined as coupons, gifts, and comment events provided by franchise companies on SNS media (Jung, Jung, \& Han, 2019; Park, Cho, \& Byun, 2019).

\subsection{Relationship between SNS Marketing Activities and Brand Recognition}

A brand is the sum of elements that can represent the identity of the brand, such as design, symbol, name, logo, etc. that sellers use to distinguish their products and services from competitors, presenting unseen quality information (American Marketing Association, 2020). Brand recognition is the ability of potential customers to recall a brand in a particular product group (Brand awareness) or to immediately withdraw certain brand information kept in their memories (Brand recall) (Aaker, 2004). Keller (2001) argued that Brand Recognition is a concept of the ability to distinguish a particular brand among different brands, and consists of four stages: the lowest level of non-recognition, brand awareness, 
brand recall, and initial recall. Brand recognition acts as an association of product images, increases familiarity and favorability with products, gives trust to products and companies, and includes specific products in purchase considerations. Therefore, brand recognition is linked to familiarity and affinity with products and businesses, which develops into trust in the company and products and services, giving a positive effect on purchasing behavior (Aaker, 2004).

In a study of SNS marketing activities and brand awareness, Min (2020) suggested that SNS marketing activities of airlines have a positive effect on brand recognition and corporate image, which results in a positive effect on purchase intention through this. Kim \& Lee (2017) revealed that SNS marketing activities of a food service company have a positive effect on brand recognition, playing a mediating role for purchase intention. In a study on airlines, Chung \& Lee (2018) have revealed that the informationality, interactivity, and multimedia features of SNS marketing have a positive effect on brand recognition. These studies suggested that inducing voluntary participation of customers, and providing engaging content to increase brand recognition, conducting SNS marketing activities through intimate communication with customers, as well as market competitiveness, increases consumer purchase intention.

This study established the following hypothesis under the premise that SNS marketing activities of franchise companies would have a significant positive effect on brand recognition.

H1: The SNS marketing activities of franchise chicken store will have a significant positive (+) effect on brand recognition.

H1-1. SNS advertising will have a significant positive (+) effect on brand recognition.

H1-2. SNS information will have a significant positive (+) effect on brand recognition.

H1-3. SNS events will have a significant positive (+) effect on brand recognition.

\subsection{Relationship between SNS Marketing Activities and Brand Familiarity}

From various perspectives, researchers are approaching the conceptual definition of brand familiarity. Familiarity was defined as an individual's memory of a stimulus object in a gradually complex and elaborate memory structure through repetitive processes of stimulus exposure, encoding, and representation (Mowen, 1995). Brand familiarity is a subjective assessment of the experience, amount of information, and level of knowledge accumulated by consumers about a place or specific experience (Prentice,
2003). It is an essential factor in maintaining long-term relationships with customers (Bae, Kim, \& Oh, 2019; Ray \& Chiagouris, 2009).

Brand familiarity is a lasting variable that reflects the level of direct or indirect customer experience of products and services, and as the experience and knowledge of products and services accumulate, goodwill and confidence in the brand increases. Consumers build awareness of the brand, services, location, products, etc. through direct and indirect experiences such as advertising, word of mouth, the purchasing experience, and interaction with store staff (Tam, 2008). In other words, brand familiarity is the intimacy with a particular brand that consumers have learned from experience, and the willingness to purchase a brand that they are familiar with is higher than a brand that they are unfamiliar with in their initial purchase behavior. Kim \& Kim (2015) argued that consumers increased brand familiarity with various experiences with the brand, remember familiar brand product advertising better than a less familiar one, and are less affected by competitive product advertising.

This study established the following hypothesis under the premise that SNS marketing activities of franchise companies will have a significant positive effect on brand familiarity.

H2: The SNS marketing activities of franchise chicken stores will have a significant positive (+) effect on brand familiarity.

H2-1. SNS advertising will have a significant positive (+) effect on brand familiarity.

H2-2. SNS information will have a significant positive (+) effect on brand familiarity.

H2-3. SNS events will have a significant positive (+) effect on brand familiarity.

\subsection{Relationship between SNS Marketing Activities and Purchase Intention}

Purchasing intention is a subjective individual will that encompasses the relationship between the consumer itself and its behavior, and was defined as an intermediate variable between individual behavior and attitude (Fishbein \& Ajzen, 1975). Aaker (2004) argued that the propensity of the consumer to take a specific action concerning the purchase of the product. Blackwell, Miniard, \& Engel (2001) defined it as an intention about what to buy in future. In Korea, researchers define purchase intention as consumer's possibility of purchasing a specific product in future. Park \& Cho (2012) have reported that it is highly probable that beliefs and attitudes will be transferred to behavior as a consumer's planned future behavior, the basis of the actual purchase behavior, the content of the purchase psychological activity, and predicting the purchase behavior. 
In a study on SNS marketing activities and the purchase intention, Lee (2018) argued that a company's SNS marketing activities play a significant role in enhancing the company's trademark asset, purchase intention, and brand loyalty. In a study on airlines, Min (2020) suggested that SNS marketing activities increase the brand recognition and trademark awareness perceived by consumers, eventually increasing the purchase intention for the products and services provided by the company. Kim \& Lee (2017) suggested that, through a study on foodservice companies, SNS marketing activities increased the brand recognition perceived by consumers as well as the satisfaction level, increasing purchase intention for foodservice products and services.

This study established the hypothesis as follows under the premise that SNS marketing activities of franchise companies will have a significant positive effect on purchase intention.

H3: The SNS marketing activities of franchise chicken stores will have a significant positive (+) effect on consumer's purchase intention.

H3-1. SNS advertising will have a significant positive (+) effect on purchase intention.

H3-2. SNS information will have a significant positive (+) effect on purchase intention.

H3-3. SNS events will have a significant positive (+) effect on purchase intention.

\subsection{Relationship between brand recognition, brand familiarity, and purchase intention}

The result of previous studies showed that brand recognition is correlated with brand familiarity. Kim \& Lee (2017) analyzed the impact relationship of brand assets on brand familiarity, brand image, and purchase intention. In this study, brand recognition among brand assets showed a positive effect on brand familiarity, and finally, it was observed that it had a positive effect on purchase intention. Kim \& Nam (2019) argued that brand recognition of casual restaurants has the most significant influence on brand familiarity and that the parent company's brand familiarity had a significant positive effect on the attitude of the extended brand. Lee \& Kim (2020), who have studied the relationship between brand safety, advertising attitude, brand attitude, purchase intention, and brand familiarity, argued that brand safety, brand knowledge, brand awareness, etc. have a positive causal relationship with brand familiarity and as a result, these factors increase the preference and purchase intention of specific products, and consumers are more likely to purchase products with high brand familiarity among multiple product options.

This study established the hypothesis as follows under the premise that brand recognition will have a significant positive effect on brand familiarity.
H4: Brand recognition of franchise chicken stores will have a significant positive (+) effect on brand familiarity.

It was observed that brand recognition has a positive effect on purchase intention(Ilyas, Rahmi, Tamsah, Munir, \& Putra, 2020). Cho (2019) argued that the brand recognition of a franchise company forms a positive brand attitude and then increases purchase intention through the brand attitude. Lim \& Koo (2019) argued that the intimacy and originality of character design positively affect brand recognition, and brand recognition raises purchase intention. Kim \& Lee (2018) argued that the coffee brand's recognition plays a moderating role in increasing purchase intention, and that brand recognition is essential to increase purchase intention.

This study established the hypothesis as follows under the premise that brand recognition will have a significant positive effect on purchase intention.

H5: Brand recognition of franchise chicken stores will have a significant positive (+) effect on purchase intention.

The relationship between brand familiarity and intention to purchase have been revealed in various fields. In a study on the structural causal relationship between the life insurance company's brand familiarity, brand image, perceived risk, trust, and purchase intention, Huh \& Choi (2016) argued that brand familiarity strengthens customer trust, increasing repurchase intention. Choi \& Ryoo (2017) suggested that the brand familiarity of fashion clothing stores has a positive causal relationship with store image, emotional trust, and repurchase intention. In a study on the purchase intention of consumers about hotel price discounts, Kim \& Kim (2019) argued that the higher the price discount rate, the higher the risk perception about quality, and the hotel's brand familiarity has a moderating effect that reduces the risk perception about quality. Kim, Yang, \& Lee (2016) also argued that brand familiarity plays a moderating role in the relationship between the perceived value of eco-friendly clothing products and purchase intention.

This study established the hypothesis as follows under the premise that brand familiarity will have a significant positive effect on purchase intention.

H6: Brand familiarity of franchise chicken stores will have a significant positive (+) effect on purchase intention.

\subsection{Moderating effect of Gender}

The demographic characteristics of consumers affect value, psychological state, and behavior in the course of purchasing behavior (Reinartz \& Kumar, 2000). Gender is an essential criterion for segmenting the market, playing a 
significant role in consumers' purchasing behavior (Han, Hsu, Lee, \& Sheu, 2011; Kim \& Yang, 2020). Jang (2020) argued that there are differences in SNS usage experience and SNS usage attitudes according to gender. Yang, Han, \& Hwang (2020) argued that the motives for using mobile-based sports media differ according to the gender. According to previous studies, it can be assumed that there may be differences based on gender in the process of consumers using and accepting SNS and reaching their purchasing intentions.

This study established the following hypothesis on the premise that gender will play a significant moderating role in the structural relationship between the SNS marketing activities, brand recognition, brand familiarity, and purchase intention.

H7: Gender will play a significant moderating role in the relationship between SNS marketing activities, brand recognition, brand familiarity, and purchase intention of the franchise chicken store.

\section{Research Design}

\subsection{Research Model}

As a result of a comprehensive summary of the preliminary research on the relationship between SNS marketing and purchasing intention of franchise chicken stores, the need for research on the causal relationship between SNS marketing activities, brand recognition, brand familiarity, and purchase intention was raised. The research model established based on this is shown in $<$ Figure $1>$.

Through the research model, this study tried to analyze how the SNS marketing activities provided by franchise chicken stores affect brand recognition, brand familiarity and purchase intention perceived by consumers, and the role of gender in the relationship between these research concepts.

\subsection{Sample Design and Research Methods}

From February 1 to February 20, 2020, a survey was conducted on adult male and female with experience in purchasing products from franchise chicken stores and using SNS by direct interview method and simple random sampling method through online questionnaire. Three hundred seven valid responses, excluding non-response data and untrustworthy data, were used for empirical analysis.

The data were analyzed using SPSS version 24 and AMOS version 24 programs and the analysis procedure followed is as follows. First, a frequency analysis was conducted to identify the demographic characteristics of the sample. Second, through confirmatory factor analysis (CFA) and correlation analysis, average variance extracted (AVE) and construct reliability (C.R) were calculated to verify the central feasibility, the validity of discrimination, and the validity of the law. Third, the hypothesis was verified by analyzing the Structural Equation Model (SEM) using the AMOS ver. 24 Statistical Program. Fourth, multiple group analysis was conducted using AMOS ver. 24 program to verify genders' moderating effects in the proposed research model.

\subsection{Measurement of Variables}

The purpose of this study was to confirm the effects of SNS marketing activities of franchise chicken stores on brand recognition, brand familiarity, and purchase intention perceived by consumers, and to confirm the moderating effect according to gender in the relationship between these research concepts.

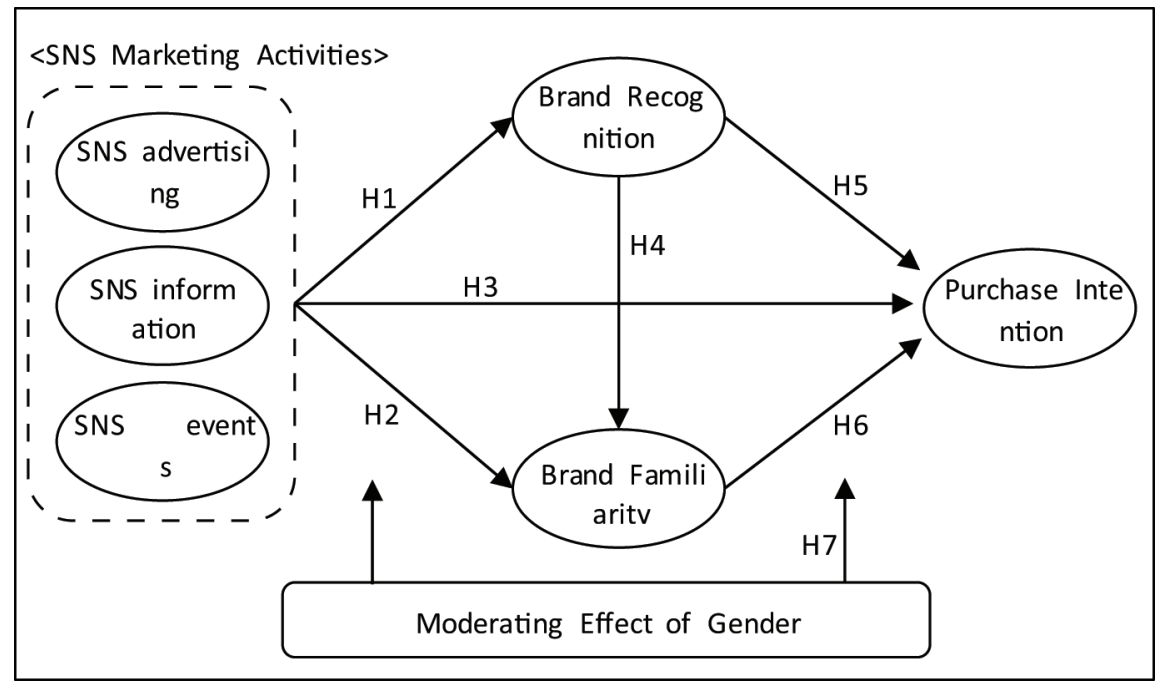

Figure 1: Research Model 
SNS marketing activities refer to plans and activities to advertise or promote products, companies, and brands using SNS, such as Twitter, Facebook, and Instagram. Based on prior studies including Ahn \& Yang (2019), Cho (2019), Delu (2019), Jung, Jung, \& Han (2019), Park, Cho, \& Byun (2019), the scale of SNS marketing activities was composed of three questions for SNS advertisement, three questions for SMS information, and three questions for SNS events. For each item, the value of the variable was measured as ' $1=$ not at all' and ' $5=$ very much' using the Likert 5-point scale.

Brand recognition is defined as the consumer's ability to identify the brand that satisfies the purchase desire among several products. Based on prior research such as Aaker (2004), Chung \& Lee (2018), Kim \& Lee (2017), Min (2020), three questions, including quality excellence, brand sophistication, brand harmony were prepared. For each item, the value of the variable was measured as ' $1=$ not at all' and ' $5=$ very much' using the Likert 5-point scale.

Brand familiarity is defined as the intimacy of a specific brand learned by consumers through experience. Based on prior researches such as Kim \& Kim (2015), Kim \& Nam (2019), Lee \& Kim (2020), three questions including intimacy, affinity, and attractiveness about the brand were composed. For each question, the value of the variable was measured as ' 1 ' = not at all' and ' 5 ' = 'very much' using the Likert 5-point scale.

Purchase intention is defined as the consumer's behavioral tendency and will to purchase products and services. Based on previous studies such as Blackwell, Miniard, \& Engel (2001), Kim \& Lee (2017), Lee (2018), Min (2020), three questions, including purchase intention for other products, continuous purchase intention, and recommendation intention were composed. For each question, the value of the variable was measured as ' 1 ' = 'not at all' and ' 5 ' = 'very much' using the Likert 5-point scale.

\section{Results and Discussion}

\subsection{General characteristics of the subject}

According to the general characteristics of the subject of 307 people used in the analysis, there were 202 males $(65.8 \%)$ and 105 females $(34.2 \%)$. As for age, 74 people $(24.1$ percent) were less than 30,138 (45 percent) were in their $30 \mathrm{~s}, 59$ (19.2 percent) were in their $40 \mathrm{~s}$, and 36 people (11.7 percent) were 50 and older. As for the marital status, 158 were married $(51.5 \%)$, and 149 were unmarried (48.5\%). As for the occupations, $68(22.1 \%)$ were office workers, $48(15.6 \%)$ professional, $121(39.3 \%)$ self-employed, public servants, and service businesses, 8 (2.6\%) homemakers, $27(8.8 \%)$ students, and 35 others (11.4\%). As for the educational level, $37(12.1 \%)$ graduates from high school or less, $183(59.6 \%)$ graduates from university or higher, and 87 (28.3\%) graduates from graduate school. As for average monthly income per household, $22(7.2 \%)$ was less than 2 million won, for 130 $(42.3 \%)$ it was less than 2 to 4 million won, for $90(29.3 \%)$ less than 4 to 6 million won, and for 25 less than 6 to 8 million won $(8.1 \%), 40$ people (13.1\%) more than 8 million won.

Next, as a characteristic of using SNS, on average, 98 people (31.9 percent) spent less than an hour on SNS, followed by 107 people (34.9 percent) less than one to two hours, 56 people (18.2 percent) less than two to three hours, 21 people (6.8 percent) less than three to four hours, and 25 people (8.1 percent) more than four hours. As for the preferred types of SNS, it showed community type 44 $(14.3 \%)$, blog-type $43(14 \%)$, chat type $161(52.4 \%)$ and video type $59(19.2 \%)$..

\subsection{Confirmatory Factor Analysis}

In this study, confirmatory factor analysis (CFA) was performed on the observed variables of the constructs. In the process of the confirmatory factor analysis, both the latent and observed variables used in the research model were input for analysis and added correlation and path using modification index to improve the level of fitness.

$<$ Table 1 $>$ shows the result of confirmatory factor analysis on SNS marketing activities, brand recognition, brand familiarity, and purchase intention of franchise chicken stores. In order to derive an optimal research model, the overall fit index was evaluated. The result of analysis of all constructs showed $\chi^{2}=222.423, \mathrm{df}=120, \mathrm{p}=.000, \mathrm{GFI}=.926, \mathrm{AGFI}=.901$, $\mathrm{RMR}=.039, \mathrm{NFI}=.918 \mathrm{CFI}=.960$ and indices, excluding the p-value, exceeded the criteria for evaluating model conformity (Jöreskog \& Sörborm, 1993). Also, in order to evaluate whether the scales are representative of the relevant research units, the composite construct reliability (CCR) and average variance extracted (AVE) of the constructs were calculated. Here, the CCR and AVE were found to exceed 0.7, which satisfies the criteria (CCR 0.6 or higher, AVE 0.5 or higher) suggested by Bagozzi \& Yi (1989).

\subsection{Validity Analysis for Constructs}

The discriminant validity and law validity of the constructs measured in this study are shown in $<$ Table $2>$. Discriminant validity is the degree to which different latent variables differ and should be less correlated. In this study, the method of evaluating discriminant validity can be reviewed through whether the AVE value exceeds the squared value of the correlation coefficient among constructs. If the AVE value is larger than the squared value of the correlation coefficient, we can assume that there is a discrimination validity. Besides, law validity is the degree to which one construct predicts another construct based on the theoretical background. If the correlation between latent variables coincides with the direction of the research model, it can be inferred that the validity condition is satisfied. 
Table 1: Confirmatory Factor Analysis for Consturcts

\begin{tabular}{|c|c|c|c|c|c|c|}
\hline Latent variables & Observed variables & Factor loading & Std. Error & t-value (C.R.) & AVE $^{a}$ & $\mathrm{CCR}^{\mathrm{b}}$ \\
\hline SNS advertising & $\begin{array}{l}\text { Product trait of SNS advertising } \\
\text { Brand trait of SNS advertising } \\
\text { Interest of SNS advertising }\end{array}$ & $\begin{array}{l}0.795 \\
0.753 \\
0.716\end{array}$ & $\begin{array}{l}0.078 \\
0.084\end{array}$ & $\begin{array}{l}12.674^{*} \\
12.075^{*}\end{array}$ & 0.72 & 0.89 \\
\hline SNS information & $\begin{array}{l}\text { Inportant of SNS information } \\
\text { Usability of SNS information } \\
\text { Reliability of SNS information }\end{array}$ & $\begin{array}{l}0.736 \\
0.809 \\
0.741\end{array}$ & $\begin{array}{l}0.083 \\
0.076\end{array}$ & $\begin{array}{l}12.401^{*} \\
11.662^{*}\end{array}$ & 0.68 & 0.87 \\
\hline SNS events & $\begin{array}{l}\text { Cycle of SNS events } \\
\text { Convenience of SNS events } \\
\text { Variety of SNS events }\end{array}$ & $\begin{array}{l}0.752 \\
0.863 \\
0.674\end{array}$ & $\begin{array}{l}0.094 \\
0.090\end{array}$ & $\begin{array}{l}12.790^{*} \\
10.995^{*}\end{array}$ & 0.75 & 0.92 \\
\hline Brand recognition & $\begin{array}{l}\text { Brand excellence } \\
\text { Brand sophistication } \\
\text { Brand harmony }\end{array}$ & $\begin{array}{l}0.734 \\
0.688 \\
0.680\end{array}$ & $\begin{array}{l}0.098 \\
0.099\end{array}$ & $\begin{array}{l}10.756^{*} \\
10.638^{*}\end{array}$ & 0.74 & 0.9 \\
\hline Brand familiarity & $\begin{array}{l}\text { Brand friendly } \\
\text { Brand likability } \\
\text { Brand attraction }\end{array}$ & $\begin{array}{l}0.796 \\
0.725 \\
0.773\end{array}$ & $\begin{array}{l}0.089 \\
0.075\end{array}$ & $\begin{array}{l}12.258^{*} \\
13.015^{*}\end{array}$ & 0.72 & 0.89 \\
\hline $\begin{array}{l}\text { Purchase } \\
\text { intention }\end{array}$ & $\begin{array}{l}\text { Purchase intention other } \\
\text { products within the barnd } \\
\text { Continuous purchase intention } \\
\text { Recommendation intention }\end{array}$ & $\begin{array}{l}0.758 \\
0.866 \\
0.822\end{array}$ & $\begin{array}{l}0.082 \\
0.081\end{array}$ & $\begin{array}{l}15.003^{*} \\
14.343^{*}\end{array}$ & 0.76 & 0.94 \\
\hline \multicolumn{7}{|c|}{$\begin{array}{l}X^{2}=222.423(d f=120), p=.000, X^{2} / d f=1.854, R M R=0.039, G F I=0.926, A \\
{ }^{*} p<.001 \\
\text { a: } \operatorname{AVE}(\text { average variance extracted) } \\
\text { b: } C C R(\text { composite construct reliability: } \rho c)=(\Sigma|\lambda i|) 2 /\{(\Sigma|\lambda i|) 2+\Sigma \theta \varepsilon i\}\end{array}$} \\
\hline
\end{tabular}

Table 2: Validity of Constructs

\begin{tabular}{|c|c|c|c|c|c|c|}
\hline & $\begin{array}{c}\text { SNS } \\
\text { advertising }\end{array}$ & $\begin{array}{c}\text { SNS } \\
\text { information }\end{array}$ & SNS events & $\begin{array}{c}\text { Brand } \\
\text { recognition }\end{array}$ & $\begin{array}{c}\text { Brand } \\
\text { familiarity }\end{array}$ & $\begin{array}{l}\text { Purchase } \\
\text { intention }\end{array}$ \\
\hline SNS advertising & 0.721 & & & & & \\
\hline SNS information & $\begin{array}{c}.713^{*} \\
(.508) \\
\end{array}$ & 0.684 & & & & \\
\hline SNS events & $\begin{array}{l}.541^{*} \\
(.293)\end{array}$ & $\begin{array}{l}.422^{*} \\
(.178) \\
\end{array}$ & 0.749 & & & \\
\hline Brand recognition & $\begin{array}{l}.651^{*} \\
(.424) \\
\end{array}$ & $\begin{array}{c}.632^{*} \\
(.399) \\
\end{array}$ & $\begin{array}{c}.475^{*} \\
(.226) \\
\end{array}$ & 0.744 & & \\
\hline Brand familiarity & $\begin{array}{c}.429^{*} \\
(.184) \\
\end{array}$ & $\begin{array}{l}.477^{*} \\
(.228) \\
\end{array}$ & $\begin{array}{l}.542^{*} \\
(.294) \\
\end{array}$ & $\begin{array}{c}.702^{*} \\
(.493) \\
\end{array}$ & 0.723 & \\
\hline Purchase intention & $\begin{array}{l}.605^{\star} \\
(.366)\end{array}$ & $\begin{array}{l}.506^{*} \\
(.256)\end{array}$ & $\begin{array}{l}.515^{*} \\
(.265)\end{array}$ & $\begin{array}{l}.777^{\star} \\
(.604)\end{array}$ & $\begin{array}{l}.684^{*} \\
(.468)\end{array}$ & 0.761 \\
\hline
\end{tabular}

Therefore, this study presented the AVE value, correlation coefficient, and square value of the correlation coefficient, and based on these values, the discriminant validity and law validity were investigated. That is, discriminant validity is to compare the squared value of the correlation coefficient with the AVE value. When comparing the squared value of each correlation coefficient based on the lowest AVE value (.684), it can be inferred that the validity condition is met in all constructs. In addition, the law validity is determined by determining whether it is consistent with the directionality 
of the hypothesis; since it showed that all the symbols of the correlation numbers have positive values as given in the hypothesis, it can be considered to be consistent with the law validity.

\subsection{Verification of Research hypothesis}

\subsubsection{Hypothesis Verification}

This study analyzed the structural equation model (SEM) based on the results of the confirmatory factor analysis on the measurement model to check the causal relationship between franchise chicken stores' SNS marketing activities, brand recognition, brand familiarity, and purchase intention.

As a result of verifying the overall model of this study, an optimal model with $\chi^{2}=207.923, \mathrm{df}=119, \mathrm{p}=.000, \mathrm{GFI}=.932$, AGFI $=.902, \mathrm{RMR}=.039, \mathrm{NFI}=.924 \mathrm{CFI}=.965$ was derived. Compared with the indices used as general evaluation criteria in the structural equation, this model was found to exceed all measurement criteria except the p-value, so it can be inferred that it satisfies the overall fitness of the research model. Therefore, the fitness of the structural model is judged to be sufficient to explain the causal relationship between the research concepts.

The results of the hypothesis verification of this study are shown in $\langle$ Table $3>$.

First, the result of verifying the hypothesis that SNS marketing activities of franchise chicken stores will have a significant positive effect on brand recognition showed that SNS advertising, SNS information, and SNS events have a significant positive effect on brand recognition. Among them, SNS advertising has a path coefficient of 3.333 $(\mathrm{t}$-value $=2.880 ; \mathrm{p}<.01)$, showing a significant positive effect at the $1 \%$ level of significance, which has the most significant influence. Next, SNS information was observed to have a significant positive effect at the significance level of $1 \%$ with a path coefficient of .329 (t-value $=3.140$; $\mathrm{p}<.01$ ). SNS event has a path coefficient .156 (t-value $=$ $2.041, \mathrm{p}<.05$ ), shows having a significant positive effect at a significant level of 5\%. This was consistent with the studies conducted by Kim \& Lee (2017), Chung \& Lee (2018), and Min (2020), as advertising, information, and event factors of SNS marketing activities conducted by franchise companies have all been proven to enhance their brand recognition.

Second, the result of verifying the hypothesis that the marketing activities of franchise chicken stores will have a significant positive effect on brand familiarity showed that SNS events have a significant positive effect on brand familiarity. It was observed that the SNS events have a significant positive effect at the significance level of $1 \%$ with a path coefficient of .323 (t-value $=4.162 ; \mathrm{p}<.001$ ). SNS advertising had a path coefficient of -.237 (t-value $=$ $-2.013 ; \mathrm{p}<.05$ ), which did not match the direction of the hypothesis and had a negative effect, violating the validity of the law, and this hypothesis was rejected. These findings confirm that SNS events have a direct influence on brand familiarity rather than SNS advertising or SNS information. This finding supports prior studies of Aaker (2004), as the corporate's marketing activities have a significant positive effect on brand familiarity.

Third, the result of verifying the hypothesis that SNS marketing activities will have a significant positive effect on purchase intention showed that SNS advertising has a significant positive effect on purchase intention. SNS advertising has a path coefficient .214 (t-value=2.034; $\mathrm{p}<.05$ ), showing to have a significant positive effect at a significant level of 5\%. This reveals that the company's image or product advertising activities through SNS implemented by franchise companies have a direct influence on purchase intention. This finding supports prior researches by Min (2020), Kim \& Lee (2017), and Lee (2018).

Fourth, as a result of verifying the hypothesis that brand recognition will have a significant positive effect on brand familiarity, it has a path coefficient of .635 ( $\mathrm{t}$-value $=5.591$; $\mathrm{p}<.001$ ), which shows a significant positive effect at the $1 \%$ significance level. This finding supports previous studies of Kim \& Lee (2013), Kim \& Nam (2019), Lee \& Kim (2020), and Kim (2020) that brand recognition perceived by consumers creates a positive attitude toward brand familiarity.

Fifth, as a result of verifying the hypothesis that brand recognition will have a significant positive effect on the purchase intention, the path coefficient was .491 (t-value $=3.928 ; \mathrm{p}<.001$ ), showing to have a significant positive effect at a significant level of $1 \%$. It can be inferred that the brand recognition of a company increases consumer intimacy and trust in products or services, increases perceived quality, and lowers perceived risk, thereby positively affecting the purchase intention. This finding supports previous researches of Cho (2019), Min (2020), Lim \& Koo (2019), and Kim (2018).

Sixth, the result of verifying the hypothesis that brand familiarity will have a significant positive effect on purchase intention, the path coefficient was .262 (t-value $=2.690 ; \mathrm{p}<.01)$ at the significance level of $1 \% \mathrm{~m}$ showing to have a significant positive effect. It can be inferred that brand familiarity lowers the confidence in the brand and the perceived risk of the product, raising higher purchase intention, and revisit intention. This finding supports previous studies of Huh \& Choi (2016), Choi \& Ryoo (2017), and $\operatorname{Kim} \& \operatorname{Kim}(2019)$. 
Table 3: Result of Hypothesis Verification

\begin{tabular}{|c|c|c|c|c|c|c|}
\hline Hypothesis & \multicolumn{3}{|c|}{ Path } & \multirow{2}{*}{$\frac{\text { Coefficient }}{.333}$} & \multirow{2}{*}{$\frac{\text { t-value }}{2.880^{* *}}$} & \multirow{2}{*}{$\frac{\text { Support }}{\circ}$} \\
\hline $\mathrm{H} 1-1$ & SNS advertising & $\rightarrow$ & Brand recognition & & & \\
\hline $\mathrm{H} 1-2$ & SNS information & $\rightarrow$ & Brand recognition & .329 & $3.140^{* *}$ & $\circ$ \\
\hline $\mathrm{H} 1-3$ & SNS events & $\rightarrow$ & Brand recognition & .156 & $2.041^{*}$ & o \\
\hline $\mathrm{H} 2-1$ & SNS advertising & $\rightarrow$ & Brand familiarity & -.237 & $-2.013^{*}$ & $x$ \\
\hline $\mathrm{H} 2-2$ & SNS information & $\rightarrow$ & Brand familiarity & .109 & 1.047 & $X$ \\
\hline $\mathrm{H} 2-3$ & SNS events & $\rightarrow$ & Brand familiarity & .323 & $4.162^{* \star *}$ & ○ \\
\hline H3-1 & SNS advertising & $\rightarrow$ & Purchase intention & .214 & $2.034^{*}$ & $\circ$ \\
\hline $\mathrm{H} 3-2$ & SNS information & $\rightarrow$ & Purchase intention & -.112 & -1.243 & $X$ \\
\hline H3-3 & SNS events & $\rightarrow$ & Purchase intention & .072 & 1.006 & $x$ \\
\hline $\mathrm{H} 4$ & Brand recognition & $\rightarrow$ & Brand familiarity & .635 & $5.591^{\star \star *}$ & ○ \\
\hline H5 & Brand recognition & $\rightarrow$ & Purchase intention & .491 & $3.928^{* \star *}$ & ○ \\
\hline $\mathrm{H} 6$ & Brand familiarity & $\rightarrow$ & Purchase intention & .262 & $2.690^{* *}$ & ○ \\
\hline \multicolumn{7}{|c|}{$\begin{array}{l}X^{2}=207.923(d f=119), p=.000, X^{2} / d f=1.747, R M R=0.039, \text { GFI=0.932, AGFI=0.902, NFI=0.924, CFI=0.965, RMSEA=0.049 } \\
{ }^{*} p<.05{ }^{* *} p<.01{ }^{* * *} p<.001\end{array}$} \\
\hline
\end{tabular}

Table 4: Model comparison by gender ( $\mathrm{x} 2$ difference test)

\begin{tabular}{|c|c|c|c|c|c|}
\hline Model & $x^{2}$ & df & $\Delta \mathrm{X}^{2}$ & $\Delta \mathrm{df}$ & $p$-value \\
\hline Free model & 355.444 & 240 & \multirow{2}{*}{$24.210^{*}$} & \multirow{2}{*}{12} & \multirow{2}{*}{.019} \\
\hline Constrained model & 379.654 & 252 & & & \\
\hline
\end{tabular}

\subsubsection{Analysis of the Moderating Effects of Gender among Constructs}

The purpose of this study was to investigate the moderating effect of gender in the relationship that the SNS marketing activities of franchise companies have on brand recognition, brand familiarity, and purchase intention perceived by consumers. To this end, a multiple group analysis using $\chi^{2}$ difference between groups was performed. For analysis of the moderating effect, the path coefficient was set to a free model, which shows the causal relationship, and examined the $\chi^{2}$ difference of the constrained model that the path coefficient between the two constructs is the same. If the difference $\left(\Delta \chi^{2}\right)$ between $\chi^{2}$ value calculated from the free model and the $\chi^{2}$ value from the constrained model is greater than 3.84 in the degree of freedom, it can be inferred it plays the moderating role.

As shown in <Table 4>, the difference between $\chi^{2}$ difference by gender path and $\chi^{2}$ value $(355.444, \mathrm{df}=240)$ calculated by the free model and 22 value calculated by the construed model $(379.654, \mathrm{df}=252)$ is greater than the standard of 21.03 at a significant level of $5 \%(p<.05)$ when the degree of freedom is 12 . Therefore, the difference by model, according to gender, was shown to be statistically significant.

In $<$ Table $5>$, the $\chi^{2}$ difference test was performed to verify the moderating effect through the difference in the gender path coefficient. By fixing the factor loadings of each of the 12 paths in the structural equation model of this study $(\Delta \mathrm{df}=1)$, we investigated whether $\Delta \chi^{2}$ was 3.84 or higher for each path. According to the analysis, $\Delta \chi^{2}$ was $9.181(\Delta \mathrm{df}=1 ; \mathrm{p}<.01)$ is between SNS information and brand recognition, showing significant differences at the $1 \%$ level of significance. For the male group, the path coefficient was .059 and, for the female group, .533, showing that the moderating effect between paths by gender was significant. It can be inferred that when a female group acquires information from SNS, it increases the perceived brand recognition rather than raising the purchase intention for the product through the information. Next, in the path between SNS information and purchase intention, $\Delta \chi^{2}$ was $5.928(\Delta \mathrm{df}=1 ; \mathrm{p}<.05)$, showing a significant difference at the $5 \%$ significance level. The path coefficient of the male group was .051, and that of the female group was -.519 , confirming that men rather than women are approaching purchase intention through SNS information. 
Table 5: Difference in path coefficient by gender

\begin{tabular}{|c|c|c|c|c|c|c|}
\hline \multirow{2}{*}{ Coefficient constrained } & \multicolumn{2}{|c|}{ Men $(n=202)$} & \multicolumn{2}{|c|}{ Wemen $(n=105)$} & \multirow{2}{*}{$\begin{array}{l}\text { Moderating } \\
\text { effect }\end{array}$} & \multirow{2}{*}{$\Delta \mathrm{x}^{2} / \Delta \mathrm{df}$} \\
\hline & Coefficient & t-value & Coefficient & t-value & & \\
\hline SNS advertising $\rightarrow$ Brand recognition & .447 & $2.978^{* *}$ & .218 & 1.954 & 0.229 & $1.376 / 1$ \\
\hline SNS information $\rightarrow$ Brand recognition & .059 & .577 & .533 & $3.906^{*+* x}$ & -0.474 & $9.181 / 1^{* *}$ \\
\hline SNS events $\rightarrow$ Brand recognition & .108 & 1.382 & -.007 & -.067 & 0.115 & $.725 / 1$ \\
\hline SNS advertising $\rightarrow$ Brand familiarity & -.579 & $-2.450^{*}$ & -.088 & -.540 & -0.491 & $2.812 / 1$ \\
\hline SNS information $\rightarrow$ Brand familiarity & .288 & 2.073 & -.202 & -.766 & 0.490 & $3.063 / 1$ \\
\hline SNS events $\rightarrow$ Brand familiarity & .400 & $3.661^{*+*}$ & .310 & $2.151^{*}$ & 0.090 & $.229 / 1$ \\
\hline SNS advertising $\rightarrow$ Purchase intention & -.014 & -.073 & .136 & .870 & -0.150 & $.348 / 1$ \\
\hline SNS information $\rightarrow$ Purchase intention & .051 & .485 & -.519 & -1.724 & 0.570 & $5.928 / 1^{*}$ \\
\hline SNS events $\rightarrow$ Purchase intention & .198 & $2.148^{*}$ & -.037 & -.239 & 0.235 & $1.035 / 1$ \\
\hline Brand recognition $\rightarrow$ Brand familiarity & .906 & $4.450^{*+*}$ & 1.039 & $2.676^{* *}$ & -0.133 & $.094 / 1$ \\
\hline Brand recognition $\rightarrow$ Purchase intention & .534 & $2.727^{* *}$ & 1.303 & $2.197^{\star}$ & -0.769 & $2.447 / 1$ \\
\hline Brand familiarity $\rightarrow$ Purchase intention & .190 & 1.683 & .093 & .353 & 0.097 & $.122 / 1$ \\
\hline
\end{tabular}

\section{Conclusion and Implications}

The purpose of this study was to analyze how SNS marketing activities of franchise chicken stores affect brand recognition, brand familiarity, and purchase intention and to verify whether there is a moderating effect according to gender in the relationship between constructs. The empirical analysis results and implications for the research hypothesis presented in this study are as follows.

First, it was observed that all the factors of the franchise company's SNS marketing activities, that is, SNS advertising, SNS information, and SNS events, have a positive effect on brand recognition. This confirms that the higher the consumer's contact with SNS marketing activities conducted by franchisees, the higher the consumer's perception of the brand, which has a positive effect on the brand. Therefore, it will be necessary to continue marketing activities for the brands of franchise companies through SNS media.

Second, SNS events during the marketing activities of franchise companies have a positive effect on brand familiarity. This proved that various event factors, such as quiz solving, sweepstakes lottery, user reviews lottery, and comment selection, are factors that expand the familiarity with consumers. That is, franchise companies will have to increase their brand familiarity through regular events that trigger the interest of potential customers using SNS media.

Third, SNS advertising has a positive effect on consumers' purchase intention among the marketing activities of franchise companies on SNS. This confirms that the SNS advertising activities conducted by franchise companies have a direct effect on purchase intention. It means that the SNS advertising method that reviews the purchase process, unboxing, reviews of use, and features of the product through SNS is more important, unlike the previous advertising that emphasized the image of the product, usage, necessity, and difference from competitors.

Fourth, brand recognition perceived by consumers has a positive effect on brand familiarity. This finding is that the franchise company's SNS marketing activities have a positive effect on brand recognition, enhancing brand familiarity, which means that SNS marketing activities are an essential means to increase brand recognition.

Fifth, brand recognition perceived by consumers has a positive effect on purchase intention. This shows that the marketing activities of franchise companies on SNS have increased their brand recognition and consequently have a positive effect on their purchasing intentions.

Sixth, brand familiarity perceived by consumers has a positive effect on purchase intention. This means that consumers who are frequently in contact with the marketing activities of the franchise companies will feel intimacy with the brand, which will increase their purchase intention.

Seventh, it was observed that gender plays a positive moderating role in the relationship among constructs. This finding indicates that the female group and male group have different paths and directions in which they become interested in SNS marketing activities of franchise companies, which makes it necessary to develop a more specific gender-based SNS marketing plan. 
Finally, the limitations of this study and future research challenges are as follows:

First, as this study was conducted on SNS marketing activities of franchise chicken stores, it is regrettable that it covered SNS marketing activities in the limited category of chicken stores. Therefore, further research needs to be carried out at more diverse levels.

Second, this study was conducted on consumers of franchise chicken stores. For the study on normative consumer behavior, a comprehensive and not one-off study should be necessary.

\section{References}

Aaker, D. A. (2004). Brand portfolio strategy. New York, NY: Free Press.

Ahn, E. J., \& Yang, D. W. (2019). The effects of perceived characteristics of mobile SNS for the agricultural and food on consumer attitude and purchase intention. Asia Pacific Journal of Small Business, 41(1), 1-28.

American Marketing Association. (2020). Brand. Retrieved from https://www.ama.org/topics/branding.

Bae, J. T., Kim, B. Y., \& Oh, S. H. (2019). The effects of brand value of orental medicine cosmetic on purchase intention. Journal of Asian Finance, Economics and Business, 6(2), 105-117. https:// doi.org/10.13106/jafeb.20190.vol6.no2.105.

Bagozzi, R. P. \& Yi, Y. (1989). On the use of structural equation models in experimental designs. Journal of Marketing Research, 26(3), 271-284. https://doi.org/10.2307/3172900.

Blackwell, R. D., Miniard, P. W., \& Engel, J. F. (2001). Consumer behavior. Cincinnati OH: South-Western College Publishing.

Cho, Y. S. (2019). Study on franchise brand recognition, brand attitude and purchase intention. Journal of Korean Ophthalmic Optics Society, 24(4), 375-380

Choi, C. J., \& Ryoo, C. H. (2017). The effect of image of fashion apparel stores on repurchase intention: Interaction effect of brand familiarity. Journal Korea Society of Visual Design Forum, 57(1), 19-30.

Chung, M. J., \& Lee, G. Y. (2018). Effects of airline's SNS marketing attributes on brand knowledge and purchase intention. Journal of the Aviation Management Society of Korea, 16(3), 129-145.

Delu, W. (2019). Enterprise network marketing strategy based on SNS social network. 12 th International Conference on Intelligent Computation Technology and Automation (ICICTA), IEEE, 295-299. https://doi.org/10.1109/ICICTA49267.2019.00069.

Fishbein, M., \& Ajzen, I. (1975). Belief, attitude, intention, and behavior: An introduction to theory and research. Boston, MA: Addison-Wesley Publishing.

Han, H., Hsu, L. T. J., Lee, J. S., \& Sheu, C. (2011). Are lodging customers ready to go green? an examination of attitudes, demographics, and Eco-friendly intentions. International Journal of Hospitality Management, 30(2) 345-355. https://doi. org/10.1016/j.ijhm.2010.07.008.
Huh, Y. S., \& Choi, C. J. (2016). Structural causal relationships among brand image, brand familiarity, brand knowledge, perceived risk, trust and purchase intention and mediating role of perceived risk in life insurance service. Korean Journal of Business Administration, 29(8), 1285-1311.

Ilyas, G. B., Rahmi, S., Tamsah, H., Munir, A. R., \& Putra, A. H. P. K. (2020). Reflective model of brand awreness on repurchase intention and customer satisfaction. Journal of Asian Finance, Economics and Business, 7(9), 427-438. https://doi. org/10.13106/jafeb.2020.vol7.no9.427

Jang, S. H. (2020). The influence of usage intentions of social network services in MICE industry: Focused on the gender differences. Journal of The Korea Contents Association, 20(3), 506-514. https://doi.org/10.5392/JKCA.2020.20.03.506.

Jöreskog, K. G. \& Sörborm, D. (1993). Structural Equation Modeling with the SIMPLIS Command Language. Lincolnwood, IL: Scientific Software International.

Jung, H. K., Jung, I. Y., \& Han, H. S. (2019). A study on SNS marketing communication and brand management in the airline industry. Korean Journal of Hospitality \& Tourism, 28(8), 91-110.

Keller, K. (2001). Strategic Management Building, CustomerBased Brand Equity. Marketing Management, 10(2), 14-19.

Kim, D. K., \& Kim, I. S. (2019). Investigating consumers' purchase intentions by hotel price discounts in OTAs setting: Mediating role of risk perception and moderating role of brand familiarity. Tourism Research, 44(4), 65-82.

Kim, H. J., \& Lee, H. C. (2017). Effect of food service corporate SNS marketing activity on brand awareness, consumer satisfaction, and purchase intention. International Journal of Tourism and Hospitality Research, 31(11), 195-209.

Kim, H. N., Yang, H. I., \& Lee, E. J. (2016). The moderating effects of brand familiarity in the relationship between perceived value of eco-friendly apparel products and purchase intention. Korean Journal of Human Ecology, 25(4), 423-434. https://doi. org/10.5934/kjhe.2016.25.4.423.

Kim, J. D., \& Lee, S. Y. (2018). A study on the effect of brand awareness on the buying intention of coffee choice. Korea Logistics Review, 28(5), 133-145.

Kim, J. H., \& Kim, S. H. (2015). The effects of brand familiarity and relationship quality on cross buying intentions of extended franchise brand and moderating role of relationship length. Journal of Channel and Retailing, 20(3), 63-86.

Kim, Y. E., \& Yang, H. C. (2020). The effects of perceived satisfaction level of high-involvement product choice attribute of millennial generation on repurchase intention: Moderating effect of gender difference. Journal of Asian Finance, Economics and Business, 7(1), 131-140. https://doi. org/10.13106/jafeb.2020.vol7.no1.131

Kim, Y. I., \& Nam, J. H. (2019). The effect of brand equity of casual restaurant on parent company brand familiarity and extension brand attitude. Journal of Hospitality and Tourism Studies, 21(1), 143-154. 
Lee, J. K., \& Kim, M. K. (2020). The effects of brand safety on consumer attitudes toward Ad, brand, and purchase intention in news websites: Focusing on the moderating role of brand familiarity. The Korean Journal of Advertising, 31(5), 7-32.

Lee, J. R. (2018). Influence on brand equity, purchase intention and brand loyalty from social media marketing activities. Journal of Marketing Studies, 26(2), 30-47.

Lim, S. H., \& Koo, J. J. (2019). A study on the influence of the collaboration character design characteristics on brand awareness and purchase intent: Focusing on food brands. Journal of Communication Design, 66(0), 298-316.

Min, Y. H. (2020). The effects of Airline's Social media Marketing on Brand awareness and Purchase Intention. Journal of Tourism Management Research, 24(2), 273-293

Mowen, J. C. (1995). Consumer Behavior (4th ed.). Englewood Cliffs, NJ: Pearson Prentice Hall Inc.

National Information Society Agency. (2019). Survey on the Internet Use. Retrieved from https://www.nia.or.kr/site/nia_kor/ex/bbs/ View.do?cbIdx $=99870 \&$ bcIdx $=22082 \&$ parentSeq $=22082$

Park, S. B., Cho, K. M., \& Byun, H. (2019). The effect of SNS marketing activity on emotional reaction, dance company image, consumer behavior. Journal of Korean Association of Physical Education and Sport for Girls and Women, 33(1), 1539.

Prentice, R. C. (2003). The distant familiar? Young British adults' imaginings of Australia. In R. Braithwaite and R. Braithwaite (eds.). Riding the Wave of Tourism and Hospitality Research
(CD-ROM file 133), Lismore, Australia: Southern Cross University.

Ray, I., \& Chiagouris, L. (2009). Customer retention: Examining the roles of store affect and store loyalty as mediators in the management of retail strategies. Journal of Strategic Marketing, 17(1), 1-20. https://doi.org/10.1080/09652540802619160.

Reinartz, W. J., \& Kumar, v. (2000). On the profitability of long-life customers in a noncontractual setting: An empirical investigation and implications for marketing. Journal of Marketing, 64(4), 17-35. https://doi.org/10.1509/jmkg.64.4.17.18077.

Royle, J., \& Laing, A. (2014). The digital marketing skills gap: Developing a digital marketer model for the communication industries. International Journal of Information Management, 34(2), 65-73. https://doi.org/10.1016/j.ijinfomgt.2013.11.008.

Statista. (2020). Social media \& user-generated content. Retrieved from https://www.statista.com/study/13996/text-based-usergenerated-content-statista-dossier/

Tam, J. L. M. (2008). Brand familiarity: Its effects on satisfaction evaluations. Journal of Service Marketing, 22(1), 3-12. https:// doi.org/10.1108/08876040810851914.

We are Social. (2020). DIGITAL 2020: Global Internet use Accelerates. Retrieved from https://wearesocial.com/globaldigital-report-2020.

Yang, H. J., Han, S. J., \& Hwang, H. S. (2020). Different motivational aspects for new media usage in sports. Korean Journal of Convergence Science, 9(2), 111-122. 